\title{
The Use of Visual-based Simulated Environments in Teacher Preparation
}

\author{
Sharon Judge ${ }^{1}$, Jonna Bobzien ${ }^{1}$, Ann Maydosz ${ }^{1}$, Sabra Gear ${ }^{1}$ \& Petros Katsioloudis ${ }^{1}$ \\ ${ }^{1}$ Darden College of Education, Old Dominion University, Norfolk, United States \\ Correspondence: Ann Maydosz, Darden College of Education, 116 Child Study Center, Old Dominion \\ University, Norfolk, VA, 23529, United States. Tel: 1-757-683-5372. E-mail: amaydosz@odu.edu
}

Received: January 11, 2013 Accepted: January 28, 2013 Available online: February 21, 2013

doi:10.11114/jets.v1i1.41

URL: http://dx.doi.org/10.11114/jets.v1i1.41

\begin{abstract}
While virtual technology for training in the simulation field has a long history in medicine, aviation, and the military, the application of similar emerging and innovative technologies in teacher preparation and education has been limited. TLE TeachLive ${ }^{\mathrm{TM}}$ (Teaching Learning Environment, Teaching in a Virtual Environment) [TLE] is an inventive mixed-reality environment (the blending of real and synthetic content) where prospective teachers can interact with a group of virtual students. The purpose of the virtual teaching environment of TLE is to strengthen teacher recruitment, preparation, and retention in education by allowing teachers to improve their skills with virtual students, providing a more constructive and ethical approach to learning the art of teaching. The protected environment allows pre-service teachers to utilize their emergent knowledge of behavior, diversity, and effective instruction in a flexible and safe practice environment. In this simulated environment, permission does not have to be gained to work with actual children and they are not exposed to missteps on the part of novice teachers as the teachers learn to refine their instructional techniques. This study investigated pre-service teachers' use of differential reinforcement of incompatible behavior, a set of behavior management strategies, in a simulated classroom. Results indicated that the majority of participants evidenced an increase in the use of these strategies to enhance student engagement in the classroom.
\end{abstract}

Keywords: technology, teacher preparation, classroom simulation, classroom management, behavior management

\section{Introduction}

In the second half of the twentieth century, the world was marked by a global diversification of the communications media and with it came a burgeoning visual culture that radically altered the dissemination and production of information and knowledge. In the realm of education, however, use of visual media was perceived by some as a threat to literacy while others touted it as a potentially powerful tool for educators (Goldfarb, 2002). In learning environments throughout education, the visual elements of instruction (e.g., graphic organizers, videos, charts, tables, and presentations) play an important role in learning. Well-conceived and rendered visuals help any audience understand and retain information (Wileman, 1993). According to Clark and Mathews (2000), the use of visual technology enhances learning by providing a better understanding of the topic, as well as engaging and motivating students. The development of visual technologies to train and educate has grown increasingly sophisticated and now includes virtual learning environments, often known as simulators. Simulators and simulated environments combine visual and kinesthetic engagement for learners and are considered powerful teaching tools in technical fields like medicine, engineering, and aviation. Simulation technologies are powerful educational tools that are becoming more widely used in many technical professions due to their effectiveness in providing powerful, multidimensional learning experiences (Siemens \& Tittenberger, 2009). At present, simulation technologies are most often used in two situations; a) low-frequency events that require high acuity, such as emergency landing procedures, and b) training for procedures that are irreversible, such as surgery and patient care (Damassa \& Sitko, 2010). Simulation of teaching and learning experiences, though inconsistently and scarcely utilized currently, may grow as they begin to be used more frequently for evaluating student performance, as well as for increasing communication skills, critical thinking and application of knowledge. Environments that rely on computers and computer interface devices such as static or dynamic representations of phenomena and training modules have been the easiest to adapt to provide a meaningful assessment environment. Examples include laparoscopic surgical procedures and military war fighting readiness. 
However, the creation of effective simulators based on human variables for use in teaching has been considered more difficult to achieve and, therefore, their availability has lagged behind other visual teaching technologies.

How might the use of visual-based simulated environments support teacher preparation? The need to recruit, prepare, and retool the teaching force in today's schools is well documented in the literature (Clark \& Matthews, 2000; Dieker, Hynes, Hughes, \& Smith, 2008; Hughes, Stapleton, Hughes, \& Smith, 2005), especially in critical teaching shortage areas such as mathematics, science, and special education. Although teacher preparation programs and alternative certification programs that address critical teaching shortage areas are available, most of these programs rely on traditional methods of preparing teachers to work in today's classrooms: college courses, field experiences, and some version of culminating internship or student teaching. Placement of pre-service teachers in school environments has become increasingly difficult as school divisions struggle with accountability, liability, and privacy issues, resulting in a decreasingly small number of contact hours in preparation for assuming full classroom duties for many teachers. Despite the collaborative efforts of colleges of education and school districts to make these experiences comprehensive, many beginning teachers have reported that they feel inadequately prepared (Darling-Hammond, 2003; Ingersoll, 2001).

\subsection{Visual-Based Simulated Technology for Teacher Preparation}

While visual-based technology for training in the simulation field has had a long history in medicine, engineering, and aviation, the application of emerging and innovative simulation technologies in teacher preparation and education has been limited (Hughes, Stapleton, Hughes, \& Smith, 2005). Traditional internship experiences in teacher education are rooted in the practice of having prospective teachers interact with students as during practicum assignments and as student teachers, thus using real students to help novice teachers improve their teaching skills. By contrast, in a visual-based simulated teaching environment, novice teachers can practice teaching and/or classroom management techniques, shaping their skills in a controlled environment. Additionally, novice teachers can utilize the technology as often necessary to correct and repeat their efforts.

TLE TeachLive ${ }^{\mathrm{TM}}$ is an innovative mixed-reality environment (the blending of real and synthetic content) where prospective teachers can interact with a group of virtual students (Dieker et al., 2008; Hughes et al., 2005). The purpose of the visual-based simulated teaching environment of TLE is to enhance teacher recruitment, preparation, and retention in education by allowing teachers to improve their skills with virtual students, providing a more clinical and enhanced approach to learning the art of teaching. This novel approach of a mixed-reality-based classroom experience addresses the need to improve teachers' effectiveness in managing adolescent behaviors in a way that provides for an unlimited variety of situations, while eliminating risks to both real students and novice teachers.

In the TLE mixed-reality environment, novice teachers enter a virtual setting designed to replicate a middle-school (grades $6-8$ ) classroom to work with classroom students who are virtual avatars. The personality attributes of these five adolescents are based on the adolescent development research of William A. Long (1985; 1989) and Rudolf Dreikurs (1958; 1968). According to Long’s (1989) framework on adolescence development, there are four generic personalities - aggressive-independent; aggressive-dependent; passive-independent; and passive-dependent -supplemented with zero to four ancillary traits (phobic, hysteric, obsessive/compulsive, and impulsive) in different levels of intensity. Thus, the five avatars have attributes of one of these personalities. As a result, a classroom can be populated by a group of virtual students that respond in a variety of ways that typify the attributes and behaviors unique to the middle school-age student population. Using the attributes of adolescents together with the research on facial expressions, body language, motion capture, and artificial intelligence, the developers of TLE were able to create immersive virtual reality environments that can be used to support the development of beginning teachers.

\subsection{Classroom Behavior Management Strategies}

One indicator of effective teaching in middle and high school is the quality of the teachers' classroom management skills (Weiner, 2003; Wolk, 2003). As such, classroom management coursework is required for teacher licensure in most states and provided in most university teacher preparation programs. However, a 2006 national teacher survey of 1,001 K-12 teachers across the United States, one in five first-year teachers did not feel adequately prepared to maintain order and discipline in the classroom (Markow, Moessner, \& Horowitz, 2006). Difficulty managing student behavior is frequently cited as a source of frustration for teachers and a common reason why new teachers leave the profession (Ingersoll 2001), leading experts to assert that pre-service teachers should be trained more rigorously on effective, evidence-based classroom management practices (Simonsen, Fairbanks, Briesch, Myers, \& Sugai, 2008).

Better preparation to manage student behaviors in general education teacher preparation programs may lie in 
adopting practices typically used by special education teachers who serve groups of students with disabilities. While special education teacher preparation programs ensure instruction and practice in managing individual student behaviors, such individualized and intensive instruction is infrequent in general education teacher preparation programs (Oliver \& Reschly, 2010). Given the rate of inclusion of all students with disabilities and the pressures of accountability measures, it would follow that general educators may benefit from instruction in individual behavior management strategies like differential reinforcement of incompatible behavior (DRI).

DRI is a simple and effective behavior management strategy for decreasing undesirable classroom behaviors while reinforcing desirable behaviors through verbal prompting, precise praise, and planned ignoring. To address an undesirable target behavior, the teacher consistently reinforces a desirable behavior that is incompatible with the target behavior (Wheatley et al., 2009). Teachers who use it must understand the basic principles of positive reinforcement and behavior (Auld, Belfore, \& Scheder, 2010; Shumate \& Wills, 2010). As such, it may be an ideal and portable strategy for use in a general education classroom to increase on task classroom behaviors like providing the prompted, elaborative, on topic responses that increase student engagement and learning.

Hence, this study leveraged computer simulation technologies, introducing pre-service teachers to a behavior management strategy designed to increase student engagement (DRI) and provide practice opportunities in a controlled setting. Specific research questions addressed in this study were as follows:

1. Does the instruction of pre-service teachers in DRI affect overall verbal responses by virtual students in a simulated instructional setting?

2. What is the effect of the instruction of DRI on pre-service teachers' classroom management practices in a simulated instructional setting?

3. What were the pre-service teachers' perceptions of DRI, including feedback and the simulated instructional setting?

\section{Method}

\subsection{Participants}

The research method employed a multi-element brief experimental analysis with six pre-service teacher participants and four virtual students in a simulated classroom environment (TLE). Though there are five virtual students in the simulated environment, one student, as per his assigned personality, did not exhibit either disruptive or unengaged behavior. Data was not taken on this student. Of the four avatars, two were female (aggressive-dependent and passive-independent) and two were male (passive-dependent and aggressive-dependent) representing the four generic personalities. The pre-service teacher participants were general secondary educators in a residency teaching immersion program. The six pre-service teacher participants included three women and three men who were 22 to 30 years old $(M=25$ years). They were taught several differential reinforcement of incompatible behavior (DRI) strategies aimed at increasing student engagement through on task behavior and decreasing undesirable behaviors that can interfere with student learning.

\subsection{Mixed Reality Environment}

In the mixed reality environment, a covert off-site interactor controls the actions of all five virtual students. The interactor, a person trained in acting and improvisation, puppeteers the character of the adolescent virtual students being taught by the pre-service teacher. Each time a pre-service teacher speaks to a virtual student, the interactor takes the role of the virtual student and makes both nonverbal and verbal expressions that correspond to the attributes of the virtual student. Thus, the virtual student exhibits a unique and appropriate personality and can respond to the pre-service teacher's tone of voice, appearance, and instructional efforts in a generative way. One interactor can control the actions of all five virtual students so that the small classroom represents the wide variety of behaviors seen in a typical classroom. The interactor is located in a university simulation lab and her voice and actions are projected through Skype, free software that allows video calling through an Internet connection. While the interactor can see the pre-service teachers, she remains unknown to the pre-service teachers, who see only the classroom and virtual students on a projection screen.

As the pre-service teacher interacts with the five virtual students, the interactor can increase or decrease the level of physical and verbal misbehavior or compliance displayed by the virtual students. These misbehaviors can consist of virtual students presenting more disruptive or more withdrawn behaviors (depending on the character's attributes). For that reason, a unique teaching experience can be created for each pre-service teacher. If a pre-service teacher makes an error, he or she can reenter the virtual classroom and try again to teach the same students the same concept or skill and use behavior strategies. Teaching sessions typically last five to ten minutes, but because of the interactor's ability to rapidly present a series of challenging behaviors through the 
five virtual students, pre-service teachers typically view the sessions as intensive and demanding.

\subsection{Design}

Identifying an effective behavior management strategy can be an important skill for pre-service teachers in the delivery of high quality, effective instruction to all students (Wright-Gallo, Higbee, Reagon, \& Davey, 2006). Although variations of brief experimental analysis have been used to investigate intervention effects of behavior management strategies with various student populations (Eckert, Dunn, Rosenblatt, \& Truckenmiller, 2008), there is a paucity of research in its application in the context of teacher education programs. Therefore, brief experimental analysis was used to investigate the effects of behavior management training on the instructional practice of pre-service general educators as evidenced by the verbal behaviors of virtual students in a simulated classroom environment.

The brief experimental analysis design allows for a rapid, systematic testing of treatment effects to determine the most efficacious intervention components, and to prevent extended implementation of an ineffective intervention (Kennedy, 2004, 2005; Martens \& Gertz, 2008; McComas \& Burns, 2009). This multi-element design provided a direct comparison of three different teacher training conditions in the implementation of the DRI strategy. This single subject design used each participant as his or her own control (Center \& Leach, 1984). The dependent variables in the study included the frequency measures of three types of virtual student verbal responses to teacher instruction: a) prompted - the virtual student verbalizes a response to the teacher's statement or question), b) elaborative - the virtual student verbalizes two or more word responses relevant to the lesson topic, and c) On topic - the virtual student verbalizes responses that are positively engaged on the lesson topic. For each participant, it was necessary to establish a baseline on the dependent variables.

This design also required repeated measures of the dependent variables for each participant. The three research study phases include baseline, intervention, and follow-up. The two-week baseline study phase exposed the four virtual students to their usual instruction 10-minute simulator sessions with each pre-service teacher with no other intervention provided. The nine-week intervention phase exposed the four virtual students to pre-service teacher instruction that incorporated the DRI strategy intervention over the course of three 10-minute simulator sessions with each pre-service teacher. There were three different intervention conditions to which the six pre-service teachers were initially randomly assigned: a) Group $1(N=2)$ : video training only , b) Group $2(N=$ 2): video training, followed by email feedback, then peer focus group feedback, and c) Group $3(N=2)$ : video training, followed by peer focus group feedback, then email feedback. The study follow-up phase over one 2-hour group meeting session with all of the pre-service teachers provided researchers with valuable feedback about the social validity of the DRI intervention and the perceived realism of the simulated environment.

\subsubsection{Intervention}

As part of their teacher preparation program, the pre-service teacher participants had been previously instructed in basic behaviorist principles like positive reinforcement. The independent variable in this study was training on the differential reinforcement of incompatible behavior (DRI) strategies and consisted of three intervention conditions noted above: a) video training only, b) video training, followed by email feedback, then peer focus group feedback, and c) video training, followed by peer focus group feedback, then email feedback. The initial DRI intervention was delivered by a research assistant, using a video training program to which all pre-service teachers were concurrently exposed. [The scripted training program is available from the first author of this manuscript.] In the video, an expert on DRI described the principles of DRI with the emphasis on the necessity of incorporating the DRI principles of antecedent verbal prompting (AVP), elaborative verbal prompting (EVP), precise praise (PP), and planned ignoring (PI). The video included numerous examples of how to implement each principle of DRI and was followed by a role-play scenario that demonstrated the strategies, along with feedback to the "teacher" on the effectiveness of her use of the strategies. Immediately following the initial video training, the research assistant administered a written assessment to each pre-service teacher, ensuring that mastery criterion of the DRI intervention content was gained by all. Following their assessment, all pre-service teachers were sent an email message containing their weekly simulator teaching schedule coordinated with their random intervention condition assignment. The pre-service teachers also were provided the email address of the DRI expert for follow-up questions.

\subsection{Interrater Reliability}

Interrater reliability was calculated on $25 \%$ of the videotaped sessions for each pre-service teacher (Kennedy, 2005). Interrater agreement was determined by dividing the number of agreements by disagreements and multiplying by 100 . The mean interrater reliability for Participant $G$ was $97 \%$ (range $=90-100 \%$ ), Participant I was $98 \%$ (range= $93-100 \%$ ), Participant $C$ was $97 \%$ (range= $86-100 \%$ ), Participant D was $96 \%$ (range $92-100 \%$ ), 
Participant A 97\% (range 90-100\%), and Participant F was 98\% (range 93-100\%) for all conditions and target behaviors.

\section{Results}

The effects of the instruction of pre-service teachers in DRI on overall verbal responses by virtual students and on the pre-service teachers' classroom management practices in a simulated instructional setting were analyzed by graphing the frequency of target behaviors. Formative data analysis included visual analysis of graphed baseline and intervention phase data. Results are summarized by research question, organized by pre-service teacher data, and virtual student data.

3.1 Research Question 1: Does the instruction of pre-service teachers in DRI affect overall verbal responses by virtual students in a simulated instructional setting?

Data pertaining to the frequency of appropriate verbal responding (e.g. on-topic, elaborative, and prompted responding) exhibited by the four virtual students for participants were collected during baseline and intervention sessions.

Table 1. Mean Occurrence of Positive Verbal by Virtual Students

\begin{tabular}{|c|c|c|c|c|c|c|c|c|}
\hline & & \multicolumn{3}{|c|}{ Baseline } & \multicolumn{3}{|c|}{ Session Means } & \multirow{2}{*}{$\begin{array}{l}\text { Grand } \\
\text { Means }\end{array}$} \\
\hline & & On-Topic & Elaborative & Prompted & On-Topic & Elaborative & Prompted & \\
\hline \multirow[t]{2}{*}{$\begin{array}{c}\text { Group } \\
1\end{array}$} & $\begin{array}{c}\text { Teacher } \\
\text { G }\end{array}$ & 3.75 & 7.75 & 4.25 & $\begin{array}{l}4.75 \\
(+1)\end{array}$ & $\begin{array}{c}7.67 \\
(-.08)\end{array}$ & $\begin{array}{c}5.83 \\
(+1.33)\end{array}$ & .75 \\
\hline & $\begin{array}{c}\text { Teacher } \\
\text { I }\end{array}$ & 3.67 & 7.25 & 4.25 & $\begin{array}{c}3.75 \\
(+.08)\end{array}$ & $\begin{array}{c}8.42 \\
(+1.17)\end{array}$ & $\begin{array}{c}4.08 \\
(-.17)\end{array}$ & .36 \\
\hline \multirow[t]{2}{*}{$\begin{array}{c}\text { Group } \\
2\end{array}$} & $\begin{array}{c}\text { Teacher } \\
\text { C }\end{array}$ & 7.00 & 6.25 & 6.5 & $\begin{array}{c}5.00 \\
(-2.0)\end{array}$ & $\begin{array}{c}6.83 \\
(+.58)\end{array}$ & $\begin{array}{c}7.58 \\
(+1.08)\end{array}$ & -.11 \\
\hline & $\begin{array}{c}\text { Teacher } \\
\text { D }\end{array}$ & 10.8 & 8.00 & 8.25 & $\begin{array}{c}2.84 \\
(-7.96)\end{array}$ & $\begin{array}{c}10.8 \\
(+2.8)\end{array}$ & $\begin{array}{c}5.50 \\
(-2.75)\end{array}$ & -2.64 \\
\hline \multirow[t]{2}{*}{$\begin{array}{c}\text { Group } \\
3\end{array}$} & $\begin{array}{c}\text { Teacher } \\
\text { A }\end{array}$ & 8.25 & 6.75 & 8.75 & $\begin{array}{c}6.67 \\
(-1.58)\end{array}$ & $\begin{array}{c}7.83 \\
(+1.08)\end{array}$ & $\begin{array}{c}8.58 \\
(-.17)\end{array}$ & -.22 \\
\hline & $\begin{array}{c}\text { Teacher } \\
\text { F }\end{array}$ & 3.00 & 9.00 & 6.00 & $\begin{array}{c}4.17 \\
(+1.17)\end{array}$ & $\begin{array}{c}7.25 \\
(-1.75)\end{array}$ & $\begin{array}{c}8.25 \\
(+2.25)\end{array}$ & .56 \\
\hline
\end{tabular}

Description: Table 1 shows the mean occurrences of positive verbal responding by virtual students during baseline and the three intervention sessions.

\subsubsection{Group 1}

Group 1 was comprised of pre-service teachers $G$ and I. This group received only video instruction in the DRI strategy prior to intervention session 1 in the virtual environment; however, they did not receive any feedback following intervention sessions 2 and 3 in the virtual environment. During intervention sessions for Participant G, virtual student data indicated an increase in the mean occurrence of on-topic $(M=4.75)$ and prompted $(M=5.83)$ responses. Additionally, a minimal decrease in the mean number of elaborative responses $(\mathrm{M}=7.67)$ was demonstrated during intervention for Participant G. During Participant I’s intervention sessions, virtual students demonstrated a slight increase in elaborative responses $(\mathrm{M}=8.42)$, a minimal increase in on-topic responses $(\mathrm{M}=3.75)$, and a slight decrease in the occurrence of prompted responses $(\mathrm{M}=4.08)$.

\subsubsection{Group 2}

Pre-service teachers $C$ and D were the participants in Group 2. This group received video instruction in the DRI strategy prior to intervention session 1 . Additionally, these teachers received feedback via email following 
intervention session 1 and feedback via peer focus group following intervention 2. On the whole, virtual student data for Participant $C$ indicated an increase in the mean occurrence of prompted responses $(M=5.83)$ and a decrease in the mean occurrence of on-topic $(M=5.00)$ and elaborative $(M=6.83)$ responses during intervention sessions. During Participant I intervention sessions, virtual students demonstrated a moderate increase in elaborative responses $(\mathrm{M}=10.8)$; however, moderate decreases in the mean occurrence of on-topic responses $(\mathrm{M}=2.84)$, and prompted responses $(\mathrm{M}=5.50)$ were noted.

\subsubsection{Group 3}

Group 3 was comprised of pre-service teachers A and F. This group received video instruction in the DRI strategy prior to intervention session 1 , as well as feedback via peer focus group following intervention session 1 and feedback via email following intervention 2. Overall, virtual student data for Participant A indicated an increase in the mean occurrence of elaborative responses $(M=7.83)$, a moderate decrease in the mean occurrence of on-topic responses $(\mathrm{M}=6.67)$, and a minimal decrease in the mean occurrence of elaborative responses $(\mathrm{M}=8.58)$ during intervention sessions. During Participant $\mathrm{F}$ intervention sessions, virtual students showed a moderate increase in on-topic $(M=4.17)$ and prompted $(M=8.25)$ responses. Additionally, a moderate decrease in the mean occurrence of elaborative responses $(M=7.25)$ was observed.

3.2 Research Question 2: What is the Effect of the Instruction of DRI on Pre-service Teachers' Classroom Management Practices in a Simulated Instructional Setting?

Data related to the frequency of DRI strategy application (e.g., antecedent verbal prompts (AVP), elaborative verbal prompts (EVP), precise praise (PP), and planned ignoring (PI) exhibited by each pre-service teacher in a simulated instructional setting were collected during baseline and 3 intervention sessions.

Table 2. Mean Occurrence of Differential Reinforcement of Incompatible Behaviors Strategies by Pre-service Teachers

\begin{tabular}{|c|c|c|c|c|c|c|c|c|c|c|}
\hline & & \multicolumn{4}{|c|}{ Baseline } & \multicolumn{4}{|c|}{ Session Means } & \multirow{2}{*}{$\begin{array}{l}\text { Grand } \\
\text { Means }\end{array}$} \\
\hline & & AVP & EVP & $\mathrm{PP}$ & PI & AVP & EVP & $\mathrm{PP}$ & PI & \\
\hline \multirow[t]{2}{*}{ Group 1} & $\begin{array}{c}\text { Teacher } \\
\text { G }\end{array}$ & 16 & 1 & 3 & 15 & $\begin{array}{c}18 \\
(+2)\end{array}$ & $\begin{array}{c}9.67 \\
(+8.67)\end{array}$ & $\begin{array}{c}12.33 \\
(+9.33)\end{array}$ & $\begin{array}{c}6.33 \\
(-8.67)\end{array}$ & $(2.83)$ \\
\hline & $\begin{array}{c}\text { Teacher } \\
\text { I }\end{array}$ & 18 & 4 & 8 & 14 & $\begin{array}{c}21.67 \\
(+3.67)\end{array}$ & $\begin{array}{l}4.00 \\
+/-0\end{array}$ & $\begin{array}{l}4.00 \\
(-4)\end{array}$ & $\begin{array}{c}12.00 \\
(-2)\end{array}$ & $(-.58)$ \\
\hline \multirow[t]{2}{*}{ Group 2} & $\begin{array}{c}\text { Teacher } \\
\text { C }\end{array}$ & 22 & 7 & 10 & 7 & $\begin{array}{l}33.00 \\
(+11)\end{array}$ & $\begin{array}{c}9.67 \\
(+2.67)\end{array}$ & $\begin{array}{c}11.00 \\
(+1)\end{array}$ & $\begin{array}{l}8.00 \\
(+1)\end{array}$ & $(+3.92)$ \\
\hline & $\begin{array}{c}\text { Teacher } \\
\text { D }\end{array}$ & 38 & 3 & 2 & 5 & $\begin{array}{c}30.00 \\
(-8)\end{array}$ & $\begin{array}{c}6.33 \\
(+3.33)\end{array}$ & $\begin{array}{l}4.00 \\
(+2)\end{array}$ & $\begin{array}{c}15.33 \\
(+10.33)\end{array}$ & $(+1.92)$ \\
\hline \multirow[t]{2}{*}{ Group 3} & $\begin{array}{c}\text { Teacher } \\
\text { A }\end{array}$ & 16 & 5 & 0 & 0 & $\begin{array}{c}40.33 \\
(+24.33)\end{array}$ & $\begin{array}{c}3.33 \\
(-1.67)\end{array}$ & $\begin{array}{l}6.00 \\
(+6)\end{array}$ & $\begin{array}{c}12.67 \\
(+12.67)\end{array}$ & $(+10.33)$ \\
\hline & $\begin{array}{c}\text { Teacher } \\
\text { F }\end{array}$ & 23 & 4 & 9 & 8 & $\begin{array}{c}29.33 \\
(+6.33)\end{array}$ & $\begin{array}{c}3.67 \\
(-.33)\end{array}$ & $\begin{array}{c}11.67 \\
(+2.67)\end{array}$ & $\begin{array}{c}13.33 \\
(+5.33)\end{array}$ & $(+3.50)$ \\
\hline
\end{tabular}

Description: Table 2 shows the mean occurrences of DRI strategies by each pre-service teacher during baseline and intervention sessions.

\subsubsection{Group 1}

Participant $G$ demonstrated an increased use of AVP ( $M=18.0)$, EVP (M=9.67), and PP ( $M=12.33)$ during intervention. A decrease in the use of PI ( $M=6.33)$ was noted. Participant I exhibited an increased use of AVP $(\mathrm{M}=21.7)$ and PP (4.00) during intervention. Use of EVP $(\mathrm{M}=4.00)$ demonstrated no change while a decrease in the use of PI (12.00) was noted. 


\subsubsection{Group 2}

Participant $C$ showed an increased use of all four DRI strategies during intervention with means of 33.0, 9.67, 11.0, and 8.00 respectively for AVP, EVP, PP, and PI. During intervention, Participant D displayed an increased use of EVP (M=6.33), PP (4.00), and PI (15.3) while presenting a decreased use of AVP (M=30.0).

\subsubsection{Group 3}

Participant A demonstrated an increased use of AVP ( $M=40.3)$, PP ( $M=6.00)$, and PI $(M=12.7)$ during intervention. A decrease in the use of EVP $(\mathrm{M}=3.33)$ was noted. During intervention, Participant F exhibited an increase in the use of AVP (M=29.3), PP ( $M=11.67)$, and PI (13.3). Participant F exhibited a decrease use of EVP $(\mathrm{M}=3.67)$ during intervention.

3.3 Research Question 3: What Were the Pre-service Teachers'Perceptions of DRI, Feedback, and the Simulated Instructional Setting?

While intervention data were taken on six teachers in the three intervention groups, nine received the video intervention and were asked their perceptions of the DRI intervention and the TLE simulator. Those participants in Groups 2 and 3 were asked about their experience with the two feedback modalities.

Table 3. Pre-Service Teachers' Perceptions of DRI, Feedback and the Simulated Instructional Setting

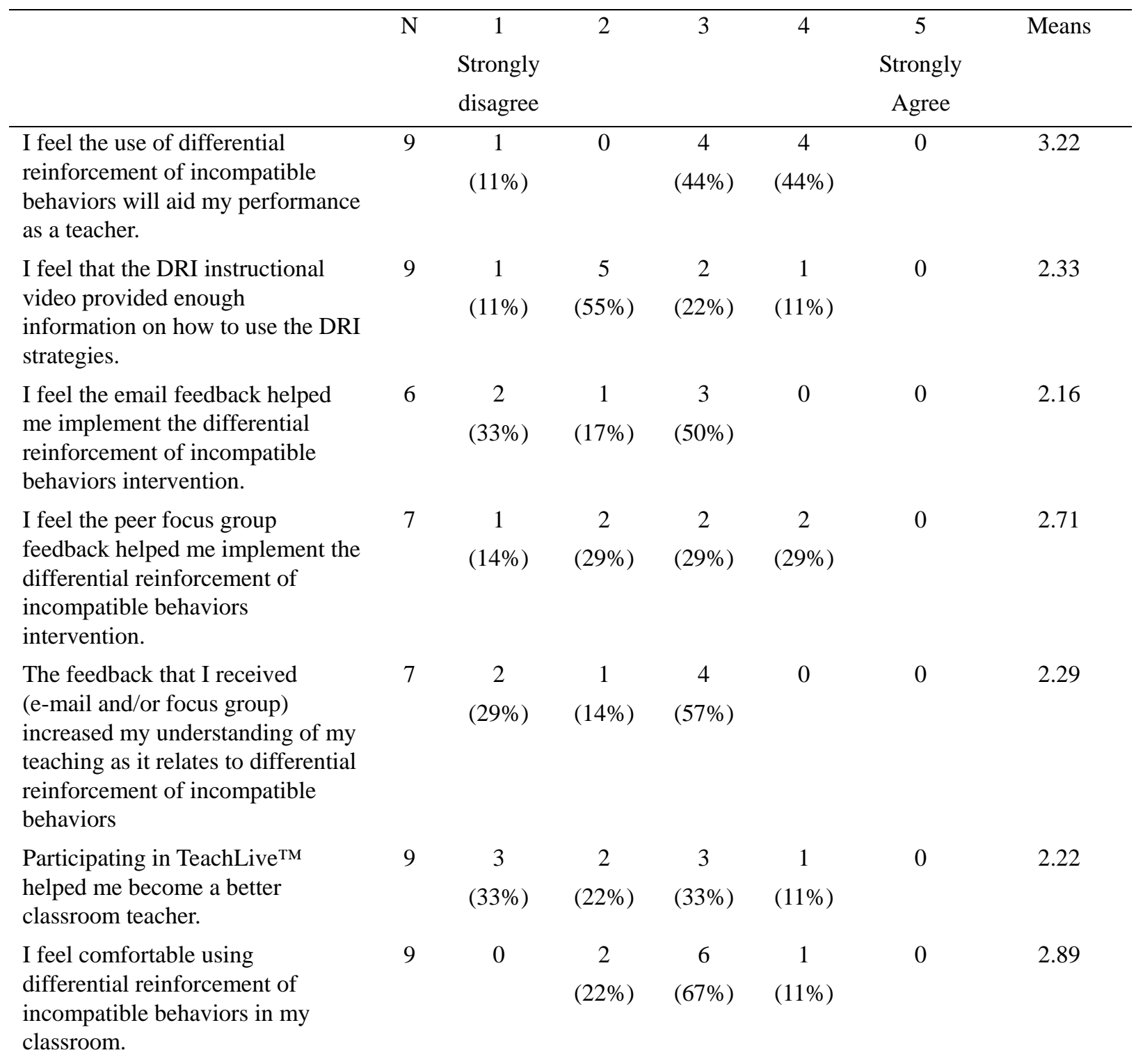

Description: Results of Group 2 and Group 3 pre-service teachers' perceptions of the DRI strategy, as well as the two feedback modalities, and the simulated instructional setting. 
Using a 5-point Likert scale ranging from 1 (strongly disagree) to 5 (strongly agree), all participants provided neutral to positive responses about their comfort using DRI techniques in their classrooms $(M=2.89)$ and the use of DRI to aid their performance as teachers $(M=3.22)$. Participants apparently felt less positive about the comprehensiveness of the DRI instructional video $(\mathrm{M}=2.33)$ and the effect of participating in TLE on their performance in the classroom (M=2.22). For those participants who received feedback (Groups 2 and 3), the usefulness of the feedback was rated at means of 2.33 for email feedback and 2.71 for peer focus group feedback. Regarding the effect of feedback in general, participants responded at neutral or negative levels $(M=2.43)$ to the statement that the feedback increased their understanding of teaching at it related to DRI techniques (see Table $3)$.

The pre-service teachers were also asked to respond to three open-ended questions. Pre-service teachers' responses to the first question: How do you feel TeachLive ${ }^{\mathrm{TM}}$ has influenced your performance as a teacher? indicated awareness of the differences between TeachLive ${ }^{\mathrm{TM}}$ and actual classroom experiences. One participant stated, “...not sure TeachLive ${ }^{\mathrm{TM}}$ was considerably beneficial compared to the real world experience I had." Another participant commented, "I don't think it has [influenced his/her performance as a teacher]—maybe if I had never stepped into a classroom." At the same time, others responded that the simulator "made me more aware of the options that I have when dealing with student disruptions," and "shows me if I am doing a strategy correctly because negative student behaviors would diminish.”

When asked the second question: What aspect of this study do you feel benefited you the most?, participants commented most often about learning a new strategy. One noted that the focus group feedback improved his/her performance in the simulator. Others commented that there were no benefits. Finally, responses to the third question: What aspect of this study do you feel benefited you the least? indicated frustration at the limitations of the virtual students. Participants commented that the virtual students' responses were “...too predictable and unchangeable" and as such were "ineffective." Another stated that use of the virtual students and not real students was a limitation, specifically, "Avatars are programmed to act a certain way so behaviors that deviate from the norm were not observed.” Other participants expressed dissatisfaction with the intervention video and timely arrival of feedback.

\section{Discussion}

Simulated teaching environments have the potential to create more and better experiential practica for pre-service teachers. In such settings, pre-service teachers may be able to practice teaching techniques like DRI without negative effects on students (Dieker et al., 2008; Hughes et al., 2005). The responsive reactions and performance of the virtual students provide important information about pre-service teachers' efforts that cannot be gained in teacher preparation classes. Because first year teachers often cite behavior disruptions as a primary source of frustration and job dissatisfaction (Ingersoll, 2001) during this study, pre-service teachers were both taught a behavior management technique and given feedback on his/her ability to implement the technique in a virtual classroom. In terms of virtual student responses to the DRI strategy, the greatest overall gains in positive responses elicited from the virtual students $(+.56)$ (on-topic, elaborative, and prompted responses from the virtual students) were made by Group 1, the group that was given the intervention but did not receive feedback. Groups 3 and 2 achieved minimal (+.17) or no (-1.38) overall gains in positive student responses (see Table 1). These results support the notion that DRI is an effective behavior management strategy for decreasing undesirable classroom behaviors, while reinforcing desirable behaviors (Wheatley et al., 2009). As such, despite participants' concerns about the DRI instructional video, participants in Group 1 may have striven to a greater degree to use the DRI techniques, resulting in changes in virtual student performance: however, the delivery of feedback appeared to have little impact on participant performance for Groups 2 and 3.

Regarding pre-service teachers' implementation of the DRI strategy as measured by their use of the four components of the DRI strategy (AVP, EVP, PP, and PI), all participants evidenced an increase in the use of these strategies. Grand means for Group 1 showed the fewest occurrences of these behaviors $(+1.14)$ while Groups 2 $(+2.92)$ and $3(+6.92)$ demonstrated greater increases. As such, despite comments regarding feedback, the groups receiving feedback demonstrated the greatest gains in the use of the DRI strategy.

In terms of the pre-service teachers' perceptions of the simulator and the DRI strategy, while some participants found it a useful setting in which to hone their teaching skills, others felt hampered by the limitations of the virtual students and the environment itself. As such, more research on the overall effectiveness of simulation settings in education should be explored. Despite noting the potential limitations of the simulated classroom environment for practicing behavior management techniques, participants indicated that learning the DRI strategy was a positive aspect of participation in the study. 
The generalizability of the results is limited by several factors. At six, the sample size of participating teachers is too small to document a strong relationship between the independent and dependent variables. However, the sample is relatively diverse and the breadth of data collected may guide additional research. Additionally, the use of a virtual classroom of student avatars lent an inherent limitation to the study. The number of supportive and confounding variables increases exponentially when actual students are added in the numbers that typically are assigned to middle school classrooms. The duration of the study may also have limited the teachers' opportunity to apply and refine the DRI strategy and may also have limited the researchers' ability to capture data trends.

Future research in this area should include maintenance and generalization probes to determine whether pre-service teachers continue to use intervention strategies that have been learned in the simulator. The interactor who controls the simulator should be supplied with a greater variety of responses to pre-service teachers' efforts in order to provide a more realistic environment. In addition, pre-service teachers who use simulators should routinely view the resulting video with their clinical faculty for instructive purposes.

Teaching is an unpredictable and highly variable endeavor. Current technology cannot effectively simulate the spectrum of possible classroom situations. However, the same is true of medical, flight and counseling simulators. As such, it is highly unusual for any professional to begin practice after preparation in simulated environments alone. However, teaching simulators do provide a responsive practice environment that results in immediate feedback from the virtual students. Videotaping of the pre-service teacher in the simulated environment also provides the opportunity for self, peer, and expert critique that can improve teaching practice. Finally, because the environment is simulated, each session in the simulator represents a fresh chance for pre-service teachers to re-try strategies and interventions for which they have received corrective feedback. In this sense, as the technology behind teaching simulators continue to improve their realism, teacher preparation programs should also maintain their efforts to provide additional, realistic practice environments for their pre-service teachers.

\section{References}

Auld, R. G., Belfore, P. J., \& Scheder, M. C. (2010). Increasing pre-service teachers' use of differential reinforcement: Effects of performance feedback on consequences for student behavior. Journal of Behavioral Education, 19, 169-183. http://dx.doi.org/10.1007/s10864-010-9107-4.

Center, D. B., \& Leach, R. (1984). The multiple baseline across subjects: A clinical research design. Journal of Manipulative and Physiological Therapeutics, 7, 231-236. Retrieved from http://www.jmptonline.org/

Clark, C. A., \& Mathews, B. (2000). Scientific and technical visualization: A new course offering that integrates mathematics, science and technology. Journal of Geometry and Graphics, 4(1), 89-98. Retrieved from http://www.heldermann.de/JGG/jggcover.htm

Darling-Hammond, L. (2003). Keeping good teachers. Educational Leadership, 60(8), 6-13. Retrieved from http://www.ascd.org/publications/educational-leadership.aspx

Dieker, L., Hynes, M., Hughes, C., \& Smith, E. (2008). Implications of mixed reality and simulation technologies on special education and teacher preparation. Focus on Exceptional Children, 40(5), 1-19. Retrieved from http://www.lovepublishing.com/catalog/focus_on_exceptional_children_31.html

Damassa, D., \& Sitko, T. (2010). Simulation technologies in higher education: Uses, trends, and implications. ECAR Bulletin Research. Boulder, CO: Tufts University

Dreikurs, R. (1958). Children: The challenge. New York: Norton.

Dreikus, R. (1968). Maintaining sanity in the classroom. New York: Harper and Row.

Eckert, T. L., Dunn, E. K., Rosenblatt, M. A., \& Truckenmiller, A. J. (2008). Identifying effective school-based reading interventions: A review of the brief experimental analysis literature. School Psychology Forum, 2(3), 16-28. Retrieved from http://www.nasponline.org/publications/spf/index-list.aspx

Goldfarb, B. (2002). Visual pedagogy. Durham, NC: Duke University Press.

Hughes, C. E., Stapleton, C. B., Hughes, D. E., \& Smith, E. (2005). Mixed reality in education, entertainment and training: An interdisciplinary approach. IEEE Computer Graphics and Applications, 26(6), 24-30. http://dx.doi.org/10.1109/MCG.2005.139

Ingersoll, R. M. (2001). Teacher turnover and teacher shortages: An organizational analysis. American Educational Research Journal, 38, 499-534. http://dx.doi.org/10.3102/00028312038003499

Kennedy, C. H. (2004). Recent innovations in single-case designs. Journal of Behavioral Education, 13, 209-211. 
http://dx.doi.org/10.1023/B:JOBE.0000044731.21352.a3

Kennedy, C. H. (2005). Single-case designs for educational research. Boston: Allyn \& Bacon. Long, W. A., Jr. (1985, March). The practitioner and adolescent medicine. Seminars in Adolescent Medicine, 1(1).

Long, W. A., Jr. (1989). Personality and learning: 1988 John Wilson Memorial address. Focus on Learning, 11(4).

Markow, D., Moessner, C., \& Horowitz, H. (2006). The MetLife survey of the American teacher, 2005-2006: Expectations and experiences. New York: MetLife Insurance Company. Retrieved from http://www.metlife.org.

Martens, B. K., \& Gertz, L. E. (2009). Brief experimental analysis: A decision tool for bridging the gap between research and practice. Journal of Behavioral Education, 18, 92-99. http://dx.doi.org/10.1007/s10864-009-9079-4

McComas, J. J., \& Burns, M. K. (2009). Brief experimental analyses of academic performance: Introduction to the special series. Journal of Behavioral Education, 18, 1-4. http://dx.doi.org/10.1007/s10864-009-9078-5

Oliver, R. M., \& Reschly, D. J. (2010). Special education teacher preparation in classroom management: Implications for students with emotional and behavioral disorders. Behavioral Disorders, 35(3), 188-199. Retrieved from http://www.ccbd.net/?q=node/9\#overlay-context=node/2\%3Fq\%3Dnode/2

Shumate, E. D., \& Wills, H. P. (2010). Classroom-based functional analysis and intervention for disruptive and off-task behaviors. Education and Treatment of Children, 33, 23-48. http://dx.doi.org/10.1353/etc.0.0088

Siemens, G., \& Tittenberger, P. (2009). Handbook of emerging technologies for learning. Retrieved from http://www.umanitoba.ca/learning technologies/celt/HETL.pdf.

Simonsen, B., Fairbanks, S., Briesch, A., Myers, D., \& Sugai, G. (2008). Evidence-based practices in classroom management: Considerations for research to practice. Education and Treatment of Children, 31, 351-380. Retrieved from http://www.educationandtreatmentofchildren.net/

Weiner, L. (2003). Why is classroom management so vexing to urban teachers? Theory into practice, 42, 305-313. http://dx.doi.org/10.1353/tip.2003.0052

Wheatley, R. K., West, R. P., Charlton, C. T., Sanders, R. B., Smith, T. G., \& Taylor, M. J. (2009). Improving behavior through differential reinforcement: A praise note system for elementary school students. Education \& Treatment of Children, 32(4), 551-571. Retrieved from http://www.educationandtreatmentofchildren.net/

Wileman, E. R. (1993). Visual communicating. Englewood Cliffs, NJ: Educational Technology Publications.

Wolk, S. (2003). Hearts and minds. Educational Leadership, 61, 14-18. Retrieved from http://www.ascd.org/publications/educational-leadership.aspx

Wright-Gallo, G. L., Higbee, T. S., Reagon, K. A., \& Davey, B. J. (2006). Classroom-based functional analysis and intervention for students with emotional/behavioral disorders. Education and Treatment of Children, 29, 421-436. Retrieved from http://www.educationandtr eatmentofchildren.net/

\section{(cc) $\mathrm{BY}$}

This work is licensed under a Creative Commons Attribution 3.0 License. 